\section{Commentary: The over and under on ischemic mitral regurgitation repair}

\author{
Nathan Haywood, MD, and Irving L. Kron, MD
}

Ischemic mitral regurgitation (IMR) is a complex pathophysiological process for which the optimal surgical management remains controversial. In a recent issue of the Journal, Xu and colleagues ${ }^{1}$ describe using a porcine model of IMR to evaluate the impact of reduction annuloplasty on left ventricular (LV) shape and functional recovery and compare it with an alternative surgical approach targeting the subvalvular apparatus, papillary muscle approximation (PMA). ${ }^{1}$ They found that although both strategies restored valvular competence at 30 days, undersizing the annulus with a rigid ring was associated with impaired LV mechanics and decreased ejection fraction compared with PMA. ${ }^{1}$ This work demonstrates yet another important contribution from this excellent group, and we read with interest as it addresses an important question: what is the best approach for repair in IMR?

Reduction annuloplasty was the standard for some time. However, this strategy has been questioned following a randomized trial reported by the Cardiothoracic Surgical Trials Network that demonstrated no difference in survival or LV end-systolic volume index at 1 year and 2 years following reduction annuloplasty compared with mitral valve replacement. ${ }^{2,3}$ However, there was an increase in the rate of recurrent regurgitation in the repair group at 2 years ( $58.8 \%$ vs $3.8 \%)$ suggesting superior durability with valve replacement. ${ }^{3}$ Leaflet tethering due to papillary muscle migration in IMR is not corrected by reduction annuloplasty and may explain high recurrence rates. As such, repair techniques addressing

\footnotetext{
From the Division of Thoracic and Cardiovascular Surgery, Department of Surgery, University of Virginia, Charlottesville, Va.

Disclosures: The authors reported no conflicts of interest.

The Journal policy requires editors and reviewers to disclose conflicts of interest and to decline handling or reviewing manuscripts for which they may have a conflict of interest. The editors and reviewers of this article have no conflicts of interest.

Received for publication Oct 5, 2020; revisions received Oct 5, 2020; accepted for publication Oct 6, 2020; available ahead of print Oct 20, 2020

Address for reprints: Irving L. Kron, MD, Division of Thoracic and Cardiovascular Surgery, Department of Surgery, 1215 Lee St, PO Box 800679 Charlottesville, VA 22908 (E-mail: ILK@ virginia.edu).

J Thorac Cardiovasc Surg 2022;164:865-6

$0022-5223 / \$ 36.00$

Copyright (c) 2020 by The American Association for Thoracic Surgery

https://doi.org/10.1016/j.jtcvs.2020.10.025
}

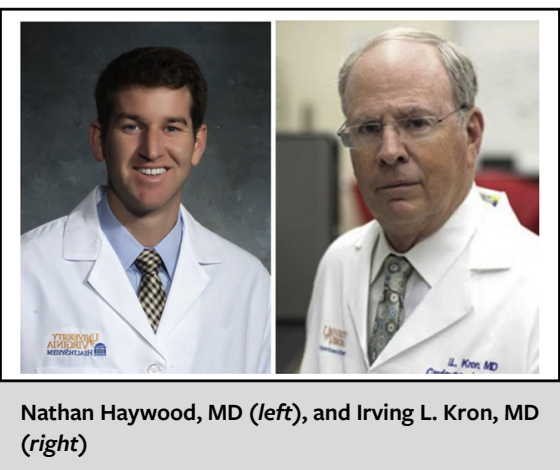

CENTRAL MESSAGE

Ischemic mitral regurgitation repair techniques should address not only the annulus, but also the subvalvular apparatus to preserve ventricular mechanics.

the subvalvular apparatus need to be more thoroughly investigated.

PMA is one approach to address leaflet tethering. A recent randomized trial demonstrated less LV remodeling, improved ejection fraction, and decreased recurrent regurgitation when PMA was performed in conjunction with reduction annuloplasty for moderate to severe IMR. ${ }^{4,5}$ This study by $\mathrm{Xu}$ and colleagues adds to the body of work suggesting that annular downsizing alone might not be the best repair, and that intervening on the subvalvular apparatus is a promising avenue. However, one limitation, as stated by the authors, is that the presented data can support multiple interpretations: that reduction annuloplasty impairs or has no effect on LV function, or that PMA improves LV function. ${ }^{1}$ It would be interesting to include a third group in which a combination approach was undertaken. This would provide additional clarity to the authors' findings. In addition, ventricular remodeling following repair develops over an extended period, and although the authors' 30-day findings are enlightening, long-term evaluation is critical to understanding the true impact on LV dynamics and risk of recurrence.

The presentation of IMR is heterogenous and might not lend itself to a one-size-fits-all repair strategy. Perhaps a nuanced approach, tailored to individual preoperative assessment, should be adopted. As the authors suggest, one effective technique in IMR may be to perform a less aggressive reduction annuloplasty combined with PMA. ${ }^{1}$ Alternatively, our group has successfully used 
surgical relocation of the posterior papillary muscle to counteract leaflet tethering. ${ }^{6}$ Although continued study is paramount to determine optimal repair strategies, we agree that future approaches should prioritize preserving physiological ventricular mechanics, and that addressing the subvalvular apparatus will be instrumental in achieving this goal.

\section{References}

1. Xu D, McBride E, Kalra K, Wong K, Guyton RA, Sarin EL, et al. Undersizing mitral annuloplasty alters left ventricular mechanics in a swine model of ischemic mitral regurgitation. J Thorac Cardiovasc Surg. 2022;164:850-61.e8.
2. Acker MA, Parides MK, Perrault LP, Moskowitz AK, Gelijns AC, Voisine P, et al. Mitral-valve repair versus replacement for severe ischemic mitral regurgitation. $N$ Engl J Med. 2014;370:23-32.

3. Goldstein D, Moskowitz AJ, Gelijns AC, Ailawadi G, Parides MK, Perrault LP, et al. Two-year outcomes of surgical treatment of severe ischemic mitral regurgitation. N Engl J Med. 2016;374:344-53.

4. Nappi F, Lusini M, Spadaccio C, Nenna A, Covino E, Acar C, et al. Papillary muscle approximation versus restrictive annuloplasty alone for severe ischemic mitral regurgitation. J Am Coll Cardiol. 2016;67:2334-46.

5. Nappi F, Spadaccio C, Nenna A, Lusini M, Fraldi M, Acar C, et al. Is subvalvular repair worthwhile in severe ischemic mitral regurgitation? Subanalysis of the Papillary Muscle Approximation trial. J Thorac Cardiovasc Surg. 2017;153: 286-95.e2.

6. Kron IL, Green GR, Cope JT. Surgical relocation of the posterior papillary muscle in chronic ischemic mitral regurgitation. Ann Thorac Surg. 2002;74:600-1. 